\title{
Estimation of Left Ventricular Diastolic Function in Gestational Hypertension during the Third Trimester Inbaghdad Teaching Hospital
}

\author{
Zainab Abdulkhaleq Al-Rikabi, M.B.Ch.B ${ }^{1}$; Ghassan T. Saeed, Msc, Phd ${ }^{2}$; \\ Ghazi Farhan Haji, MD.FICMS(Med), FICMS (Cardiol) ${ }^{3}$
}

\begin{abstract}
Background: Gestational hypertension exerts a great challenge on the maternal cardiovascular system, in spite of this fact, there is lack of reports regarding the maternal diastolic function in gestational hypertension which precedes systolic dysfunction in any cardiovascular complications.

Objectives: To evaluate the maternal left ventricular diastolic function in gestational hypertensive women in the third trimester by measuring the mitral inflow parameters with pulse wave Doppler and Tissue Doppler Imaging.
\end{abstract}

Patients and Methods: This studywas conducted in Baghdad teaching hospital from November 2015 to June 2016. Sixty gestational hypertensive womenwith singleton pregnancy in the third trimester, aged $29.7 \pm 5.9$ year, gestational hypertension was defined as systolicblood pressure that is equal or more than $140 \mathrm{mmHg}$ or diastolic bloodpressurethatequals or exceeds $90 \mathrm{mmHg}$ and starts after 20 weeks of gestation without proteinuria were enrolled in this study. Another 50 Normal pregnant womenaged $28 \pm 3.18 y e a r$ served as controls. The left ventricular diastolic function was studied using two transthoracic echocardiographic methods: Pulsed wave Doppler $(P W D)$ to measure the transmitral flow velocity including the early maximum velocity of mitral inflow( $E$ wave), the late maximum velocity of mitral inflow (A wave), and E/A ratio was recorded. Tissue Doppler imaging (TDI) to measure thelateralmitral annular velocity (lateral é), the septal mitral annular velocity (septal é) and their average (é) was calculated. The ratio of Elé was recorded.

Results:_Gestational hypertensive women hadsignificant lower E wave velocity compared tonormal pregnant women ( $P$ value was 0.001). "A" wave velocity was higher in gestational hypertensive women with statistical difference $(P$ value 0.002$)$ and E/A was significant low in gestational hypertension with $P$ value $<0.05$. Tissue Doppler imaging showed significant difference in é velocity which was lowerin gestational hypertensive women $(P$ value 0.001). E/éin gestational hypertension showed significantly higher value than controls with $P$ value $<0.05$.

Conclusion:_Gestational hypertension puts the maternal heart under pressure and volume overload associated with impaired relaxation as manifested by the changes inthe left ventricular diastolic function measured by transthoracic echocardiography.

Keywords: Gestational Hypertension; Echocardiograph; Diastolic function;Pregnancy.

\section{Introduction}

Pregnancy induces a major stress on the maternal cardiovascular system. Series of adaptation mechanisms start from as early as 5 weeks of gestationto increase oxygen delivery to the mother and the fetus(1). Maternal cardiovascular maladaptation is strongly related to pregnancy outcome(2)

Hypertensive disorders in pregnancy are associated with severe maternal obstetric complications and are of the main causes of maternal mortality(3).Furthermore, they can lead to preterm delivery, fetal intrauterine growth restriction, low birth weight and perinatal death(4). Although the exact incidence is unknown, it has been found that 5-10\% of US pregnancies are complicated by hypertensive disorders of pregnancy(5). Studying the maternal cardiovascular adaptation during pregnancy provides an insight into the interaction between maternal and fetal homeostasis and may prove a useful screening tool for pregnancy complications(6). Although impairment of diastolic function of the left ventricle (LV) precedes systolic dysfunction in the evolution of most cardiac diseases, there is a scarcity of reports on diastolic function during pregnancy (7).

Gestational hypertension affects the maternal left ventricular diastolic function, but in a unique way that differs from chronic hypertension in several aspects; it affects a cardiovascular system that was previously normal and adapted to pregnancy which itself induces many changes to the maternal heart. And it lasts for a temporary period of time (maximum of ten months) (8) and(9).

Traditionally, evaluation of Doppler patterns of mitral inflow have been used in the assessment of left ventricular diastolic function, as transmitral velocities reflect the pressure gradient between the left ventricle and the left atrium and they are highly dependent on loading conditions, heart rate and rhythm. There are two major components of normal transmitral flow: the rapid early filling phase (E wave) and filling associated with atrial 
Estimation Of Left Ventricular Diastolic Function In Gestational Hypertension during The Third..

contraction (A wave). The transmitral flow is normal when E:A ratio is slightly greater than one and relatively brisk with (150-220 ms) E wave deceleration, defined as the time from the peak of the Ewave to the end of early mitral flow. The atrial contribution to ventricular filling typically does not exceed $20 \%$. The normal mitral filling and the four patterns of diastolic function are shown in the figure 1 and 2 (10) and (11).

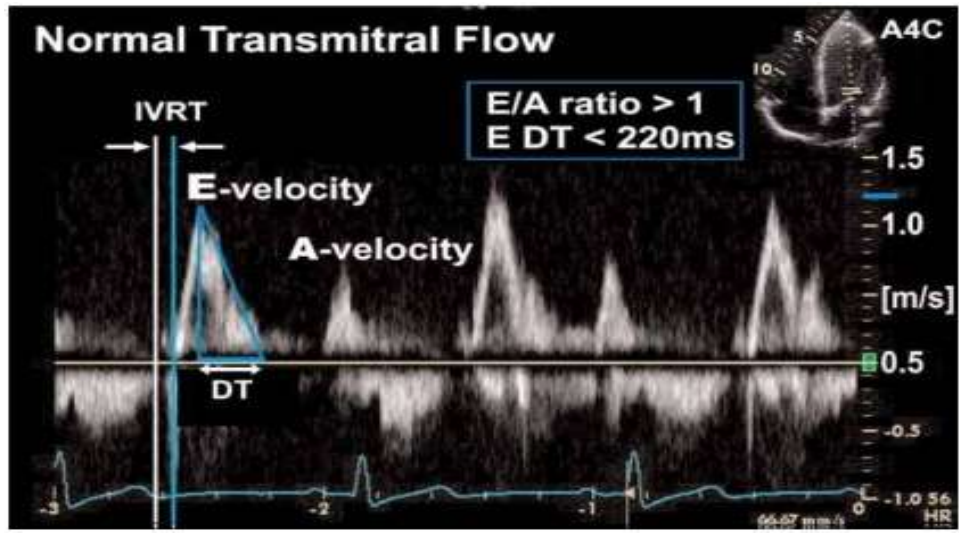

Fig.1. Pulse wave Doppler of normal transmitral flow patternduring diastole sampled at the tips of the mitral leaflets using the apical four chamber view.

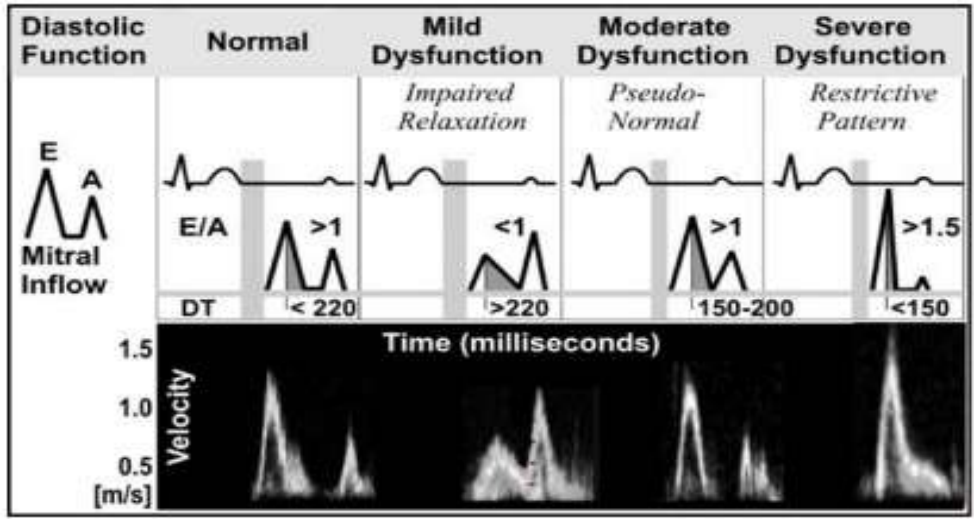

Fig.2: transmitral Doppler flow pattern showing normal filling, impaired relaxation (A wave $>$ E wave), pseudonormal filling and restrictive filling ( $\mathrm{E}$ wave $>\mathrm{A}$ wave; increased $\mathrm{E}$ wave velocity and shortened $\mathrm{E}$ wave deceleration time). These patternsforms the basis of grading diastolic function from mild to severe.

Tissue Doppler imaging (TDI) is an echocardiographic technique for assessing the diastolic function that is relatively independent of preload (13). Since loading conditions change significantly during pregnancy, a load-independent technique will give a more accurate assessment of the diastolic function in pregnant women. (12). TDI measures the early diastolic velocity of the longitudinal motion of the mitral annulus (é) which reflects the rate of myocardial relaxation.Decreased mitral annular velocity(é) is one of the earliest markers for diastolicdysfunction and is present in all stages of diastolic dysfunction. Because é velocity remainsreduced and mitral E velocity increases with higher fillingpressure, the ratio between transmitral E and é (E/é)correlates well with LV filling pressure according toASE/EACVI GUIDELINES AND STANDARDS(14). And shown in Fig.
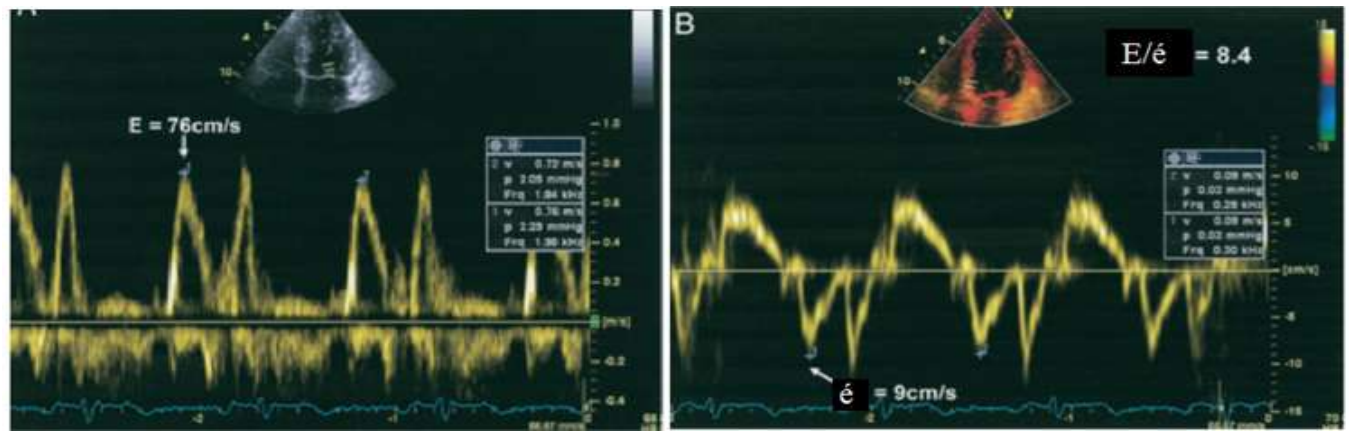

Fig. 3 Estimation of left ventricular diastolic pressure by the ratio of transmitral E (A) and mitral septal annular velocity (B), E/é.The E/é ratio in this patient is 8 , which is within normal limits. 


\section{Methods}

60 women with gestational hypertension32-40 weeks of gestation with singleton pregnancy, gestational hypertension was diagnosed when systolic blood pressure was equal or over $140 \mathrm{mmHg}$ or diastolic blood pressure equals $90 \mathrm{mmHg}$ or higher without proteinuria $(<300 \mathrm{mg} / \mathrm{dl})$ in resting sitting position $(8)$. Ten patients were excluded; (four patients' age was less than 20 year old, two had twin pregnancy, one patient showed small pericardial effusion, one patient had aortic regurgitation, one had mitral valve prolapse and one had hyperthyroidism). Another control group of 50 women, with singleton normotensive pregnancy matched for age and gestational age were enrolled in this study during the same time period.Inclusion criteria were: 1) Singleton uncomplicated pregnancy. 2) Age 20-40 year old. 3) During the third trimester. 4) BP $\geq 140 / 90 \mathrm{mmHg}$ measured in the left lateral decubitus position. 5) No proteinuria ( $<300 \mathrm{mg} / \mathrm{dl})$. 6) Normal fetal parameters and amniotic fluid index (confirmed by ultrasound in the same hospital). Exclusion criteria: 1) All complications of pregnancy (congenital fetal abnormalities, placenta previa, accreta....etc). 2) Essential hypertension. 3) Ischemic heart diseases. 4) DM. 5) Valvular heart disease. 6) Anemia. 7) Dyslipidemia. 8) Thyroid dysfunction. 9) Smoking.

All patients were referred from the obstetrics clinic at Baghdad teaching hospital and examined at the department of echocardiography and catheterization in the $8^{\text {th }}$ floorof the same hospital from November 2015 to May 2016.

Their blood pressure was measured in the left lateral decubitus position, to overcome the pressure of the gravid uterus on the inferior vena cava, after a period of 15 min of rest using adult size MDF mercury sphygmomanometer and stethoscope.

Echocardiography: All patients were examined with PHILIPS CX10 diagnostic ultrasound system equipped with a S5-1, 2.5 MHz transducer. Examination was performed in left lateral decubitus position from the parasternal and apicalwindows, by three observers to avoid bias in results. Pulsewave Doppler imaging was used to measure the Mitral inflow velocity in the apical 4 chamber view by placing PW Doppler sample volume (1-3 mm axial size) betweenmitral leaflet tips with low wall filter setting (100-200 MHz) and low signal gainaccording to the guideline summary of 2016 (14). The early maximum velocity (E) of mitral filling and the late maximum velocity of mitral filling $(\mathrm{A})$ was recorded, and E/A ratio was calculated.

TissueDoppler imaging was used to measure the lateral annular motion of the mitral leaflets (é), placing the PW Doppler sample volume (5-10 mm axial size) at the lateral mitral annulus (lateral é), the septal mitral annulus (septal é), their average was obtained (é) and the ratioE/é was calculated.

\section{Results}

Table (1) comparison of Patient Characteristics between GHW and controls.

\begin{tabular}{|c|c|c|c|c|c|c|c|c|c|c|}
\hline \multirow[t]{2}{*}{ Parameters } & \multicolumn{2}{|l|}{ Age } & \multicolumn{2}{|c|}{ Weight } & \multicolumn{2}{|l|}{ Height } & \multicolumn{2}{|l|}{ BSA } & \multicolumn{2}{|l|}{ BMI } \\
\hline & Cases & Ctrls & Cases & Ctrls & Cases & Ctrls & Cases & Ctrls & Cases & Ctrls \\
\hline Mean & 29.7 & 28 & 90.2 & 79.14 & 1.58 & 1.57 & 1.991 & 1.861 & 35.97 & 31.85 \\
\hline St & 5.936 & 3.182 & 7.982 & 6.117 & 0.0573 & 0.0573 & 0.0974 & 0.0886 & 4.074 & 2.912 \\
\hline $\mathbf{T}$ & \multicolumn{2}{|l|}{1.785} & \multicolumn{2}{|l|}{7.776} & \multicolumn{2}{|l|}{0.714} & \multicolumn{2}{|l|}{6.986} & \multicolumn{2}{|l|}{5.825} \\
\hline Mean difference & \multicolumn{2}{|l|}{1.7} & \multicolumn{2}{|l|}{11.06} & \multicolumn{2}{|l|}{0.008} & \multicolumn{2}{|l|}{0.13} & \multicolumn{2}{|l|}{4.125} \\
\hline P-value & \multicolumn{2}{|l|}{0.077} & \multicolumn{2}{|l|}{0.001} & \multicolumn{2}{|l|}{.477} & \multicolumn{2}{|l|}{0.001} & \multicolumn{2}{|l|}{0.001} \\
\hline
\end{tabular}

This study showed that the mean age for cases was $29.7 \pm 5.936$ year compared to $28 \pm 3.182$ year for controls, with mean difference of 1.7 year, but this difference was statistically insignificant ( $\mathrm{p}$-value $>0.05$ ). Cases had a mean weight of $90.2 \pm 7.982 \mathrm{~kg}$ compared to $79.14 \pm 6.117 \mathrm{~kg}$ with mean difference of $11.06 \mathrm{~kg}$, and a significant statistical association between them (P value 0.001), there was no statistical difference in height ( $\mathrm{P}$ value 0.477 ) and as result their BMI and BSA also showed statistically significant difference (p-value $<0.05$ for both), as cases had $35.97 \pm 4.074 \mathrm{~kg} / \mathrm{m}^{2}$ (morbid obesity) and controls had $31.85 \pm 2.912 \mathrm{~kg} / \mathrm{m}^{2}$ (obese), for BSA, the cases had a mean of $1.991 \pm .0974 \mathrm{~m}^{2}$ compared to $1.861 \pm .0886 \mathrm{~m}^{2}$ for controls

Table (2): Comparison of gestational age between study samples.

\begin{tabular}{|l|l|l|l|l|l|l|}
\hline Groups & $\begin{array}{l}\text { Mean Gestational } \\
\text { Age }\end{array}$ & Sd & T & DF & Mean difference & P-value \\
\hline Cases & 35.14 & 2.821 & 1.39 & 98 & .660 & .168 \\
\hline Control & 34.48 & 1.821 & & \\
\hline
\end{tabular}


Gestational age in Table (2). Showed mean gestational age for GHW $35.14 \pm 2.821$ weeks compared to $34.48 \pm 1.821$ weeks for controls, having a mean difference of 1.39 week, but there was no statistically significant difference between the two age groups ( $p$-value $>0.05$ ).

Table (3): Comparison of gravidity and parity between study samples.

\begin{tabular}{|c|c|c|c|c|}
\hline \multirow{2}{*}{ Parameters } & \multicolumn{2}{|c|}{ Gravidity } & \multicolumn{2}{c|}{ Parity } \\
\cline { 2 - 5 } & Cases & Controls & Cases & Controls \\
\hline Mean & 3.84 & 2.92 & 2.18 & 1.56 \\
\hline Sd & 1.963 & .853 & 1.60 & .837 \\
\hline T & \multicolumn{2}{|c|}{3.040} & \multicolumn{2}{c|}{2.428} \\
\hline Mean difference & \multicolumn{3}{|c|}{.920} & \multicolumn{2}{c|}{.020} \\
\hline \multicolumn{2}{|c|}{.003} & \multicolumn{2}{c|}{.017} \\
\hline P-value & \multicolumn{3}{|c|}{ Standard deviation, T: independent Sample Test, Degree of freedom = 98 } \\
\hline
\end{tabular}

Both gravidity and parity showed significant statistical differences between cases and controls with $\mathrm{p}$ value $<0.05$, as shown in Table (3), cases had mean gravidity of $3.84 \pm 1.963$ vs. $2.92 \pm .853$ in controls with $P$ value of 0.003 and mean parity of $2.18 \pm 1.60$ for GHW vs. $1.56 \pm .837$ in controls and $\mathrm{P}$ value of 0.017 .

Table (4) demonstrates thepulse wave Dopplerechocardiographic parameters that assessed the mitral inflow velocities, there were significant statistical difference between cases and controls in early (E), late (A) ventricular filling velocity and E/A ratio, as shown in Table (3), the mean E velocity for cases was $88.85 \pm$ $17.44 \mathrm{~ms}$ compared with $101.6 \pm 13.56 \mathrm{~ms}$ in controls, having absolute mean difference of $12.74 \mathrm{~ms}$ it was significantly lower in case group ( $\mathrm{P}$ value 0.001). Also the same for A velocity, it was significantly higher in case group $91.27 \pm 27.02 \mathrm{~ms}$ compared to $77.00 \pm 17.032$ in controls, $\mathrm{P}$ value 0.002 . E/A ratio was significantly higher in controls $(1.36 \pm .267)$ than cases $(1.05 \pm .369)$ with $\mathrm{P}$ value 0.001 . In this study 30 gestational hypertensive women $(60 \%)$ had E/A less than 1 and $6(12 \%)$ cases of 50 who had their E/A ratio more than 1.53 , only one had E/A more than 2 .

Table (4) Mitral inflow velocity pattern between cases and controls measured with pulse wave Doppler.

\begin{tabular}{|c|c|c|c|c|c|c|}
\hline \multirow[t]{2}{*}{ Parameters } & \multicolumn{2}{|c|}{$\begin{array}{l}\text { E } \\
\text { Velocity }\end{array}$} & \multicolumn{2}{|c|}{$\begin{array}{l}\text { A } \\
\text { Velocity }\end{array}$} & \multicolumn{2}{|l|}{$\begin{array}{l}\text { E/A } \\
\text { Ratio }\end{array}$} \\
\hline & Cases & Ctrls & Cases & Ctrls & Cases & Ctrls \\
\hline Mean & 88.85 & 101.6 & 91.27 & 77.0 & 1.05 & 1.36 \\
\hline Sd & 17.44 & 13.56 & 27.02 & 17.03 & .369 & .267 \\
\hline $\mathbf{T}$ & \multicolumn{2}{|l|}{4.078} & \multicolumn{2}{|l|}{3.159} & \multicolumn{2}{|l|}{4.933} \\
\hline Mean difference & \multicolumn{2}{|l|}{12.74} & \multicolumn{2}{|l|}{14.27} & \multicolumn{2}{|l|}{.318} \\
\hline P-value & \multicolumn{2}{|l|}{0.001} & \multicolumn{2}{|l|}{0.002} & \multicolumn{2}{|l|}{0.001} \\
\hline
\end{tabular}

Ctrls: controls, SD: Standard deviation, T: independent Sample Test,Degree of freedom = 98

Regarding Tissue Doppler Imaging, theaverage diastolic peak velocities of themitral annulus (é) was significantly lower in cases than controls, $12.055 \pm 2.35 \mathrm{~ms}$ and $16.414 \pm 1.678 \mathrm{~ms}$ respectively, with absolute mean difference of $2.833 \mathrm{~ms}$ and $\mathrm{P}$ value 0.001 . Also E/é ratio showed significant statistical difference between cases and controls, as the mean difference was 1.273 , with $7.488 \pm 1.43$ in casescompared to controls $6.214 \pm$ .730 (P value 0.001). As shown in Table (5).

Table (5) Mitral annular velocity measurements using tissue Doppler imaging in gestational hypertension (cases) and normotensive pregnancy (controls)

\begin{tabular}{|c|c|c|c|c|}
\hline \multirow{2}{*}{ Parameters } & \multicolumn{2}{|c|}{$\begin{array}{c}\text { average mitral annularé } \\
\text { velocity }\end{array}$} & \multicolumn{2}{c|}{ E/ératio } \\
\cline { 2 - 5 } & Cases & Ctrls & Cases & Ctrls \\
\hline Mean & 12.055 & 16.414 & 7.488 & 6.214 \\
\hline Sd & 2.35 & 1.678 & 1.43 & .730 \\
\hline T & \multicolumn{2}{|c|}{10.667} & \multicolumn{2}{c|}{5.595} \\
\hline Mean difference & \multicolumn{2}{|c|}{4.358} & \multicolumn{2}{c|}{1.273} \\
\hline P-value & \multicolumn{2}{|c|}{.001} & .001 \\
\hline
\end{tabular}

Ctrls: controls, Sd: Standard deviation, t: independent Sample Test,

Degree of freedom $=98$

\section{Discussion}

Normal pregnancy is a well-known cause of increased cardiac output and circulatory volume with decrease in peripheral resistance (15).

It has been established that increased weight is strongly related to the development of hypertension (16). Overweight pregnant women are more likely to develop gestational hypertension. (17). This study showed 
significant relation between body mass index and body surface area with gestational hypertension with $\mathrm{P}$ value less than 0.05 for both of them. This comes in agreement with Shin Dand Song WO (18).

Studying the left ventricular diastolic function using Pulse Wave Doppler revealed significant decrease in the early mitral filling velocity ( $\mathrm{E}$ wave), significant increase in late mitral filling velocity (A wave) so that E/A ratio was reversed and significantly lower in gestational hypertension, $30 \mathrm{GHW}(60 \%)$ had their E/A less than 1. This means gestational hypertensive women had mild diastolic dysfunction (grade I) with normal LV end diastolic pressure but impaired relaxation according to theEAE/ASE Recommendations for evaluating left ventricular diastolic function (19).This comes in agreement with Kyoung Im Cho and colleagues, who found significant decrease in E/A ratio, increase in A wave velocity but he found that E wave velocity didn't change significantly (20). Unlike Karen Melchiorre and team who found that gestational hypertensive women didn't haveany evidence of significant global diastolic (21).

The results of Tissue Doppler Imaging in the current study showed that average é was significantly lower in gestational hypertensive women with significant increase in E/ é and 15 GHW (30\%) had their E/é $\geq 8$. It is noteworthy to mention thatLV filling pressures are related to the ratio of the mitral inflow $\mathrm{E}$ wave to the tissue Doppler é wave (E/é) as have been studied using cardiac catheterization and echocardiography. This correlation is based on the fact that é velocities "corrects" E-wave velocities which is dependent on preload and relaxation (22). Gestational hypertensive women in the present study according to E/é have the upper normal LV end diastolic pressure and 30\% of them might have elevated LV diastolic pressure. These results come in agreement with Orsolya Szenczi and János Rigó Jr.who found significant increase in A wave velocity, significantly lower E/A and significantly higher E/é in gestational hypertension. (23). and on the contrary Vlahović-Stipac and colleaguesshowed that gestational hypertension didn't have significant impact on the maternal left ventricular diastolic function and E/é remained unchanged. (24). We conclude from these information that gestational hypertension imposes pressure and volume overload on the left ventricle during a short period of time in a previously normal cardiovascular system and might lead to mild diastolic dysfunction as measured with pulsed wave Doppler and confirmed by tissue Doppler imaging.

\section{References}

[1]. Lisa A. Simmons, Adrian G. Gillin and Richmond W. Jeremy. Structural and functional changes in left ventricle during normotensive and preeclamptic pregnancy. Am J Physiol Heart Circ Physiol.2002, 283: H1627-H1633.

[2]. Ouzounian JG, Elkayam U. Physiologic changes during normal pregnancy and delivery. Cardiol Clin. 2012, 30: 317-329.

[3]. Ahmed, R.; Dunford, J.; Mehran, R.; Robson, S.; Kunadian, V. Pre-eclampsia and future cardiovascular risk among women: A review. J. Am. Coll. Cardiol. 2014, 63: 1815-1822.

[4]. Barbosa, I.R.; Silva, W.B.; Cerqueira, G.S.; Novo, N.F.; Almeida, F.A.; Novo, J.L. Maternal and fetal outcome in women with hypertensive disorders of pregnancy: The impact of prenatal care. Ther. Adv. Cardiovasc. Dis. 2015, 9: 140-146.

[5]. IOM (Institute of Medicine) and NRC (National Research Council). 2009. Weight Gain during Pregnancy: Reexamining the Guidelines. Washington, DC: the National Academies Press. December 10, 2012.

[6]. Cusimano, M.C.; Pudwell, J.; Roddy, M.; Cho, C.K.; Smith, G.N. The maternal health clinic: An initiative for cardiovascular risk identification in women with pregnancy-related complications. Am. J. Obstet. Gynecol. 2014, 210: e431-e439

[7]. N. A. Kametas, F. McAuliffe, J. Hancock, J. Chambers and K. H. Nicolaides. Maternal left ventricular mass and diastolic function during pregnancy. Ultrasound Obstet Gynecol 2001, 18: 460-466.

[8]. Visintin C, Mugglestone MA, Almerie MQ, Nherera LM, James D, Walkinshaw S, 2010 Management of hypertensive disorders during pregnancy: summary of NICE guidance. BMJ 341: c2207.

[9]. Karen Melchiorre, George Ross Sutherland, Aigul Baltabaeva, Marco Liberati, Basky Thilaganathan. Maternal Cardiac Dysfunction and Remodeling in Women with Preeclampsia at Term. Hypertension. 2011, 57:85-93.

[10]. Scott D.Solomon and Bernard Bulwer (eds).Essential echocardiography book. Totowa, New Jersey. Humamna Press Inc. 2007, $122-123$.

[11]. Nagueh SF, Appleton CP, Gillebert TC, et al. Recommendations for the evaluation of left ventricular diastolic function by echocardiography. J Am Soc Echocardiogr. 2009 Feb, 22(2):107-33.

[12]. W. Y. Fok, L. Y. Chan, J. T. Wong, C. M. Yu and T. K. Lau. Left ventricular diastolic function during normal pregnancy: assessment by spectral tissue Doppler imaging. Ultrasound Obstet Gynecol 2006, 28: 789-793.

[13]. Cheuk-Man Yu, John E. Sanderson, Thomas H. Marwick, and Jae K. Oh. Tissue Doppler Imaging: A New Prognosticator for Cardiovascular Diseases. Journal of the American College of Cardiology. 2007, 49; 1903-1914.

[14]. ASE/EACVI GUIDELINES AND STANDARDS, Recommendations for the Evaluation of Left Ventricular Diastolic Function by Echocardiography: An Update from the American Society of Echocardiography and the European Association of Cardiovascular Imaging. J Am Soc Echocardiogr 2016, 29:277-314.

[15]. Monika Sanghavi, MD; John D. Rutherford, MB ChB, FRACP. Cardiovascular Physiology of Pregnancy. Circulation. 2014; 130:1003-1008.). of the National High Blood Pressure Education Program Working Group on High Blood Pressure in Pregnancy. Am J Obstet Gynecol 2000, 183:S1 - S22.

[16]. Stevo Julius, Mariaconsuelo Valentini, Paolo Palatini. Overweight and Hypertension A 2-Way Street? Hypertension. 2000, 35:807813.

[17]. Martin A, O’Sullivan AJ, Brown MA. Body composition and energy metabolism in normotensive and hypertensive pregnancy. BJOG 2001, 108:1263 - 1271.

[18]. Shin D and Song WO. Prepregnancy body mass index is an independent risk factor for gestational hypertension, gestational diabetes, preterm labor, and small- and large-for-gestational-age infants. J Matern Fetal Neonatal Med. 2015, 28(14):1679-86.

[19]. Sherif F. Nagueh, Chair, Christopher P. Appleton, Thierry C. Gillebert, Paolo N. Marino, Jae K. Oh, Otto A. Smiseth, Alan D. Waggoner, Frank A. Flachskampf, Patricia A. Pellikka and Arturo Evangelisa. Recommendations for the Evaluation of Left Ventricular Diastolic Function by Echocardiography. European Journal of Echocardiography. 2009, 10: 165-193. 
[20]. Kyoung-Im Cho, Seong-Man Kim, Mi-Seung Shin, Eui-Joo Kim, Eun-Joo Cho, Hae-Sun Seo, Sung-Hee Shin, Se-Jung Yoon, Jung-Hyun Choi. Impact of Gestational Hypertension on Left Ventricular Function and Geometric Pattern. Circulation journal. 2011, 75: $1170-1176$

[21]. Karen Melchiorre, George Ross Sutherland, Aigul Baltabaeva, Marco Liberati, Basky Thilaganathan. Maternal Cardiac Dysfunction and Remodeling in Women With Preeclampsia at Term. Hypertension. 2011; 57:85-93.

[22]. Carolyn Y. Ho, Scott D. Solomon. A Clinician's Guide to Tissue Doppler Imaging. Circulation. 2006, 113:e396-e398.

[23]. Orsolya Szenczi, János Rigó Jr. Maternal left ventricular dysfunction and remodeling in pregnancy complicated with gestational hypertension. Pregnancy Hypertension. July 2015, 5(3), 232.

[24]. Vlahović-Stipac A Stankić V, Popović ZB, Putniković B, Nesković AN.Left ventricular function in gestational hypertension: serial echocardiographic study. American Journal of Hypertension. 2010 Jan, 23(1):85-91. 